\title{
COMPARISON OF GNSS PWV AND ERA5-DERIVED PWV BASED ON GNSS PWV IN HONG KONG, CHINA
}

\author{
Zongwan $\mathrm{Li}^{1}$, Changzeng Tang ${ }^{2,}$, Shihua Tang ${ }^{1}$, Yue Zhang ${ }^{1}$ \\ ${ }^{1}$ Surveying and Mapping Engineering,College of Geomatics and Geoinformation, Guilin University of Technology, Guilin, 541006, \\ China-58650875@qq.com \\ ${ }^{2}$ Guangxi Zhuang Autonomous Region Geographical Conditions Monitoring Institute, Nanning, 530000, China -
} 349930978@qq.com

Commission VI, WG VI/4

KEY WORDS: GNSS, PWV, ERA5, ZTD, Hong Kong

\begin{abstract}
:
Water vapor is the most abundant atmospheric gas, and it plays a vital role in the evolution of the Earth's climate. Precipitable water vapor (PWV) is a key factor in monitoring the climate and hydrological cycle. The use of GNSS to estimate PWV is a very effective method. This paper uses 17 satellite positioning reference stations in the Satellite Positioning Reference Station Network in Hong Kong, China, in 2017 to calculate the PWV and introduce the latest reanalysis data set of European Centre for Medium-Range Weather Forecasting (ECMWF) ERA5 into this study. The accuracy of ERA5-derived PWV was evaluated using the GNSS-derived PWV. In Hong Kong, the annual bias and RMSE values of GNSS-derived ZTD and ERA5-derived ZTD are $1.16 \mathrm{~cm}$ and $1.78 \mathrm{~cm}$, while the annual RMSE values of GNSS-derived PWV and ERA5-derived PWV are $0.51 \mathrm{~cm}$ and $0.57 \mathrm{~cm}$. The daily changes of GNSS PWV in 2017 are analyzed, and the results show that the ZTD effect of ERA5 reanalysis data derived in the small range area is not very ideal, but the accuracy of the PWV derived from ERA5 is better.
\end{abstract}

\section{INTRODUCTION}

The troposphere is the lowest layer in the Earth's atmosphere, about 7 to 20 kilometers from the Earth's surface, where almost all climate change occurs. Water vapor in the troposphere plays a key role in global climate change and atmospheric processes (Holloway and Neelin, 2010; Torres et al., 2010; Wang et al., 2017). As an important component of the atmosphere, and as one of the most varied components in the troposphere, water vapor is highly involved in global water cycle and energy exchange(Zhang et al., 2019). In order to monitor and evaluate changes in the weather system, it is extremely important to accurately understand the distribution and changes of atmospheric water vapor. Ground to atmosphere top level cross sectional area The total amount of water vapor in the air column condenses into rain. The rainfall is usually called Precipitable water vapor (PWV). The ground-based GNSS water vapor estimation PWV technology provides a new means for tropospheric water vapor detection. Compared to traditional atmospheric water vapor detection, GNSS can be used in all weather conditions with low cost and high spatial and temporal resolution (Nilsson and Gradnarsky, 2006; Jin et al., 2007).

The concept of GNSS (Global Navigation Satellite System) Meteorology was first developed by Beavis and others. (1992) it is proposed that the use of ground-based GNSS-derived PWV

* Corresponding author 
has been widely used in meteorology. Especially for weather forecasting, there have been many scholars involved in the study (Fudeyasu et al., 2008; Benevides et al., 2015; Yao et al., 2017; Zhao et al., 2018 a). Monitoring extreme weather with GNSS PWV (Heffernan, 2013; Wang et al., 2018). Improvements to weather forecasting models (Gendt et al., 2004; Yang et al., 2013). In some small regions, these places have established a regional GNSS continuous operation reference station network, using these established GNSS continuous operation reference station network can be calculated based on the local PWV, which provides more ideas for studying the accuracy of GNSS PWV products in small areas.

In July 2017, the ECMWF released the fifth-generation reanalysis data set of ERA5 with a horizontal resolution of 31 $\mathrm{km}$ (Olauson, 2018). For the ERA5, the atmosphere is divided into 137 model levels from the Earth surface up to a height of $80 \mathrm{~km}$ and also interpolated to 37 pressure levels. Its temporal resolution reaches $1 \mathrm{hr}$ (Albergel et al., 2018). Its data is available at https://cds.climate.copernicus.eu. The accuracy of a small range of ERA5-derived PWV can be evaluated using a small range of GNSS-derived PWV.

\section{DATA SOURCES AND POLICIES}

\subsection{Data sources}

Since the key parameter affecting GNSS-derived PWV is Zenith stratospheric delay (ZTD), the discussion of ZTD is added to the following study. This paper selects data from SatRef 2017 in Hong Kong, China, with the titles HKCL, HKKS, HKKT, HKNP, HKOH, HKPC, HKQT, HKSC, HKSS, HKST, HKTK, HKWS, T430, a total of 17 stations. Its geographic location is shown in Figure 1.

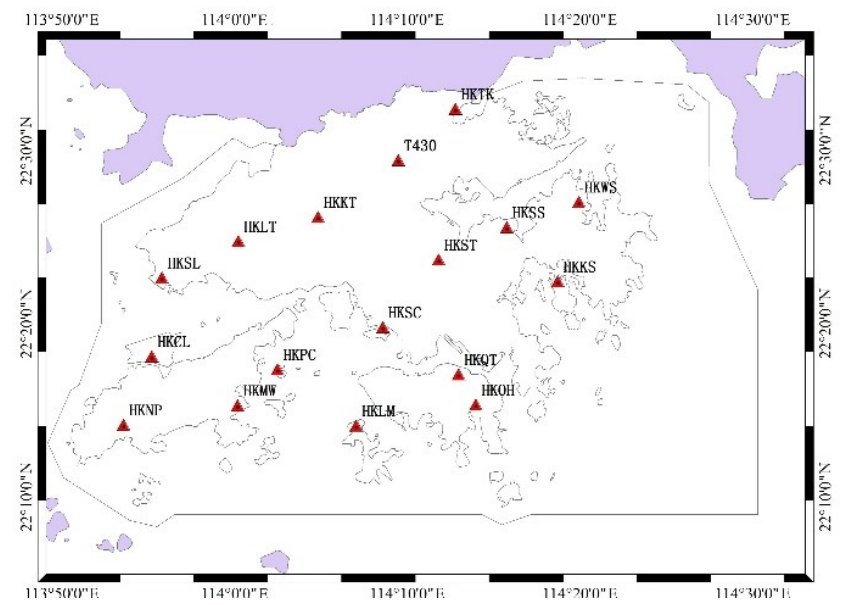

Figure 1. SatRef point distribution map of Hong Kong

In addition, get the data for the same time of ERA5 hourly estimates of the variables on the pressure levels' with a horizontal resolution of $0.25^{\circ} \times 0.25^{\circ}$, covering pressure $\mathrm{P}(\mathrm{hPa})$, geopotential $\mathrm{Z}\left(\mathrm{m}^{2} \cdot \mathrm{s}^{2}\right)$, temperature $\mathrm{T}(\mathrm{K})$, Specific humidity $\mathrm{q}\left(\mathrm{kg} \cdot \mathrm{kg}^{-1}\right)$, relative humidity $\mathrm{R}(\%)$, etc.

\subsection{Processing Policies}

Eighteen satellite positioning reference stations are processed using GAMIT 10.7 software and using the double-difference mode (Herring et al., 2010). The specific strategy is as follows: GNSS observation sampling rate of $30 \mathrm{~s}$, height cut-off angle of $10^{\circ}$, convective correction model using VMF1 model, $2 \mathrm{~h}$ estimated once ZTD (B hm et al., 2006). Use the precise ephemeris and broadcast ephemeris calendars provided by MGEX to participate in the solution. At the same time, accurate ZTD predictions were obtained using the global tidal model FES2004 (http://holt.oso.chalmers.se/loading/).

After obtaining the GNSS ZTD prediction, the GNSS-derived PWV can be calculated according to the formula (1) (2):

$$
\text { ZWD=ZTD-ZHD }
$$

$$
\mathrm{PWV}=\Pi \cdot \mathrm{ZWD}
$$

Dry delay ZHD can be calculated by the Saastamoinen model (Saastamoinen, 1972):

$$
\mathrm{ZHD}=0.0022768 \cdot \frac{\mathrm{P}_{\mathrm{s}}}{1-0.00266 \cos (2 \varphi)-0.00028 \mathrm{H}}
$$

$$
\begin{array}{ll}
\text { where } & \mathrm{P}_{\mathrm{S}}=\text { surface pressure } \\
& \varphi=\text { latitude } \\
& \mathrm{H}=\text { geodetic height of GNSS station }
\end{array}
$$

The conversion coefficient is calculated as follows (Bevis et al., 1992, 1994):

$$
\Pi=\frac{10^{6}}{\rho_{\omega} \cdot \mathrm{R}_{\mathrm{v}}\left[\frac{\mathrm{k}_{3}}{T_{m}}+\mathrm{k}_{2}^{\prime}\right]}
$$


where

$\rho_{\omega}=$ liquid water density

$\mathrm{R}_{\mathrm{v}}=461.495 \mathrm{~J} /(\mathrm{kg} \cdot \mathrm{K})$ specific gas constant of water

vapor

$\mathrm{T}_{\mathrm{m}}=$ weighted average temperature

The weighted average temperature $T_{m}$ is calculated as follows (Davis et al., 1985):

$$
\mathrm{T}_{\mathrm{m}}=\frac{\int_{\mathrm{h}_{0}}^{\mathrm{h}_{\mathrm{top}}} \frac{\mathrm{e}}{\mathrm{T}} \mathrm{dh}}{\int_{\mathrm{h}_{0}}^{\mathrm{h}_{\text {top }}} \frac{\mathrm{e}}{\mathrm{T}^{2}} \mathrm{dh}}
$$

where

$$
\begin{aligned}
& \mathrm{T}=\text { temperature } \\
& \mathrm{e}=\text { partial vapor pressure }
\end{aligned}
$$

Partial vapor pressure can be calculated according to the formula (6) (Lagler et al., 2013).

$$
\mathrm{e}=\mathrm{q} \cdot \frac{\mathrm{P}}{0.622}+0.378 \mathrm{q}
$$

where

$$
\begin{aligned}
& \mathrm{q}=\text { specific humidity } \\
& \mathrm{e}=\text { air pressure }
\end{aligned}
$$

Using ERA5 estimation of ZTD, for the top level data, there is little impact on wet delay, the Saastamoinen dry delay model can be used to solve The ZTD. The remaining layers estimate that ZTD is generally calculated by integration (Chen et al., 2012; Huang et al.,2018).

$$
\mathrm{ZTD}_{\text {top }}=0.0022768 \cdot \frac{P_{\text {top }}}{1-0.00266 \cos (2 \varphi)-0.00028 \mathrm{~h}_{\text {top }}}
$$

where

$$
\begin{aligned}
& P_{\text {top }}=\text { top pressure value } \\
& h_{\text {top }}=\text { corresponding position height of the top level }
\end{aligned}
$$

$$
\mathrm{ZTD}_{\mathrm{l}}=10^{-6} \int_{\mathrm{h}_{0}}^{\mathrm{h}_{\text {top }}} \mathrm{Ndh}=10^{-6} \sum_{\mathrm{i}=1}^{\mathrm{n}} \mathrm{N}_{\mathrm{i}} \Delta \mathrm{s}_{\mathrm{i}}
$$

where $\quad \mathrm{N}=$ atmospheric refraction index
The $\mathrm{N}$ calculation formula such as (9).

$$
\mathrm{N}=\frac{\mathrm{k}_{1}(\mathrm{P}-\mathrm{e})}{\mathrm{T}}+\left(\frac{\mathrm{k}_{2} \mathrm{e}}{\mathrm{T}}+\frac{\mathrm{k}_{3} \mathrm{e}}{\mathrm{T}^{2}}\right)
$$

$$
\text { where } \quad \begin{aligned}
\mathrm{k}_{1} & =77.604 \mathrm{~K} / \mathrm{hPa} \\
\mathrm{k}_{2} & =64.79 \mathrm{~K} / \mathrm{hPa} \\
\mathrm{k}_{3} & =377600.0 \mathrm{~K} / \mathrm{hPa}
\end{aligned}
$$

The partial vapor pressure e calculation formula is as (10).

$$
\mathrm{e}=\frac{\mathrm{qP}}{0.622}
$$

The final formula for ZTD is:

$$
\mathrm{ZTD}=\mathrm{ZTD}_{\text {top }}+\mathrm{ZTD}_{1}
$$

PWV can be derived by ERA5 reanalysis. First, the calculation formula of ZWD is derived, and the PWV derived from ERA5 is obtained by the formula (2).

$$
\mathrm{ZWD}=10^{-6} \int \mathrm{N}_{\omega} \mathrm{d}_{\mathrm{h}}=\sum_{\mathrm{i}=1}^{\mathrm{n}} \mathrm{N}_{\omega} \Delta \mathrm{h}_{\mathrm{i}}
$$

where $\quad \mathrm{N}_{\omega}=$ wet refractive index

the $\mathrm{N}_{\omega}$ formula is as follows (Davis et al., 1985):

$$
\mathrm{N}_{\omega}=\left(\mathrm{k}_{2}^{\prime} \cdot \frac{\mathrm{e}}{\mathrm{T}}+\mathrm{k}_{3} \frac{\mathrm{e}}{\mathrm{T}^{2}}\right) \cdot \mathrm{Z}_{\omega}^{-1}
$$

where $Z_{\omega}^{-1}=$ inverse compressibility level, which differs from 1 within $1 \%$ and which was set to 1 in this study.

Because the GNSS site is scattered around the ERA5 reanalysis data grid point, there is a certain deviation between the measuring site and the grid point in the vertical and horizontal direction. Since the ERA5 reanalysis data is layered according to air pressure, each layer of air pressure corresponds to a different height. If the elevaation of the to-point point is within the upper and lower boundary layers of the reanalysis data, the meteorological parameters of the location of the to be fixed point can be obtained by interpolation or integration. If the 
elevation to be fixed is below the bottom of the reanalysis data, the weather parameters can be extrapolated in the form of extrapolation. In the horizontal direction, the calculation is considered using the inverse distance-weighted interpolation method.

\section{RESULTS COMPARISON AND ANALYSIS}

\subsection{Comparison of GNSS ZTD and ERA5 ZTD in Hong Kong}

This paper estimates the ZTD value of 17 GNSS stations in Hong Kong in 2017, and uses ERA5 reanalysis data to derive ZTD, and compares the ZTD valuation of each station, as shown in Table 1. Statistical results show that the average deviation (bias) of all stations in 2017 is $1.16 \mathrm{~cm}$, and the mean square root error (RMSE) is $1.78 \mathrm{~cm}$, of which bias has the highest winter accuracy, the lowest summer, and the lowest in autumn and lowest in winter. Although each value is within 2cm, GNSS-derived ZTD and ERA5-derived ZTD are less consistent. Considering that there is no quality control in the statistics, the final statistical results may be affected by the fact that some poorly observed time periods have not been eliminated.

\begin{tabular}{|c|c|c|c|c|c|}
\hline & Spring & Summer & Autumn & Winter & Year \\
\hline bias & 0.85 & 0.56 & 1.30 & 1.92 & 1.16 \\
\hline RMSE & 1.57 & 1.44 & 1.88 & 1.25 & 1.78 \\
\hline
\end{tabular}

Table 1. ZTD bias and RMSE changes $(\mathrm{cm})$

\subsection{Comparison of GNSS PWV and ERA5 PWV in Hong Kong}

The GNSS PWV time series can be obtained by the calculation of GNSS ZTD in combination with meteorological parameters, and compared with the PWV time series calculated by the reanalysis data of ERA5. This paper analyzes the changes in the bias and RMSE of GNSS-derived PWV and ERA5-derived PWV in Hong Kong in 2017, and analyzes the seasonal variation of GNSS PWV. The results are shown in Table 2 . The statistical results show that the bias and RMSE of all stations are $0.51 \mathrm{~cm}$ and $0.57 \mathrm{~cm}$ in 2017 , and the winter bias and RMSE are the smallest in all seasons. The difference between GNSSderived PWV and ERA5-derived PWV is small, but since the estimated ZTD value is relatively inaccurate, the PWV accuracy of the two may be worse than ideal.

\begin{tabular}{|c|c|c|c|c|c|}
\hline & Spring & Summer & Autumn & Winter & Year \\
\hline bias & 0.45 & 0.48 & 0.51 & 0.20 & 0.51 \\
\hline RMSE & 0.52 & 0.55 & 0.58 & 0.37 & 0.57 \\
\hline
\end{tabular}

Table 2. PWV bias and RMSE changes $(\mathrm{cm})$

Take 3 representative stations of HKKT, HKPC and HKSS in the satellite positioning reference network in Hong Kong, and compare the daily changes of GNSS-derived PWV and ERA5derived PWV in 2017. As shown in Figure 2, Figure 3 and Figure 4, all three stations have significant seasonal variations. The spring PWV has a distinctly high peak, indicating that the spring water vapor activity is intense, in line with the characteristics of the plum rain season in Hong Kong. The PWV is lower in winter, but the PWV changes significantly, and it is guessed that more precipitation time occurred in winter. It can be observed from the figure that the GNSS-derived PWV has the highest coincidence with the ERA5-derived PWV in spring, and the PWV is different in other seasons, but the PWV trends are basically the same. It can also be seen from the figure that the difference between the GNSS-derived PWV and the ERA5-derived PWV is small, but since the estimated ZTD value is relatively inaccurate, the PWV accuracy of the two may be worse than ideal.

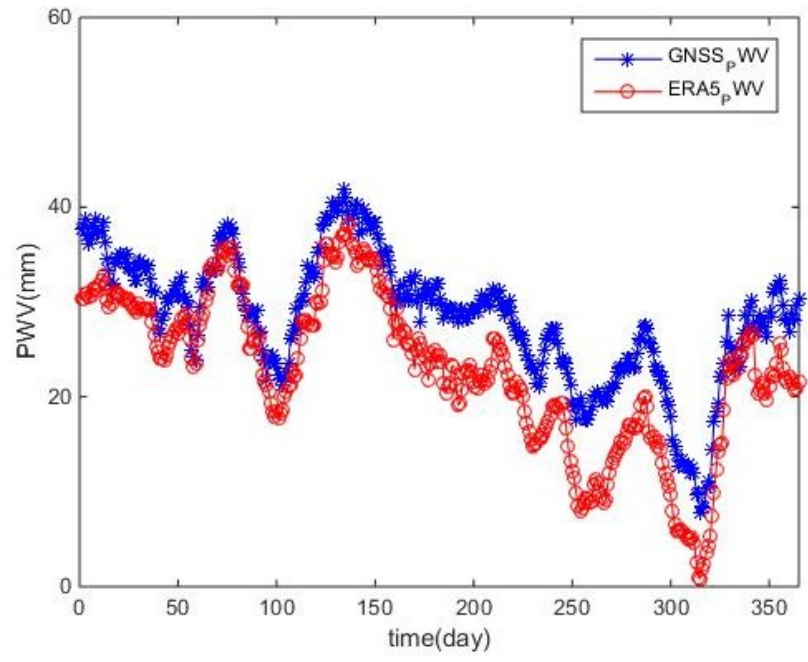

Figure 2. HKKT PWV 


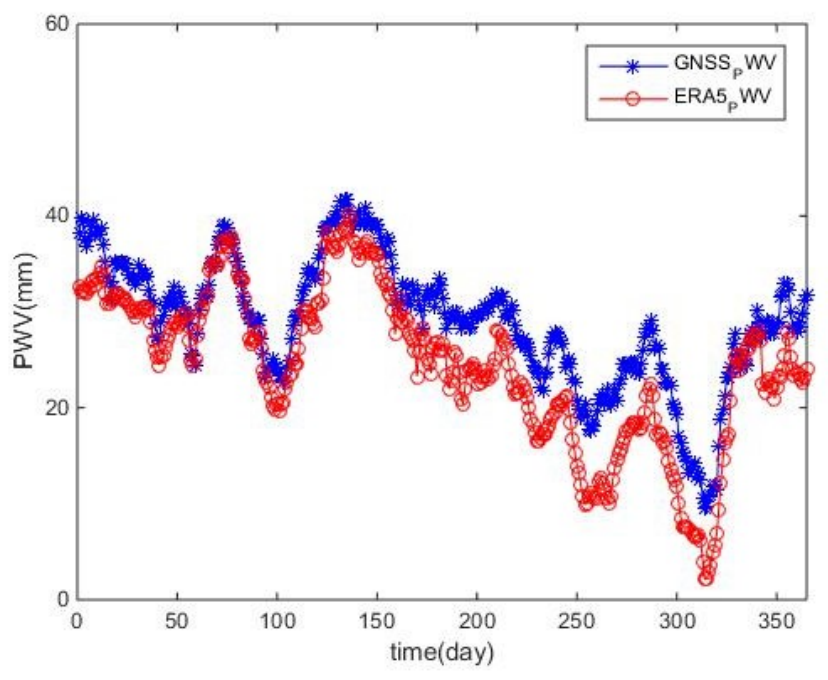

Figure 3. HKPC PWV

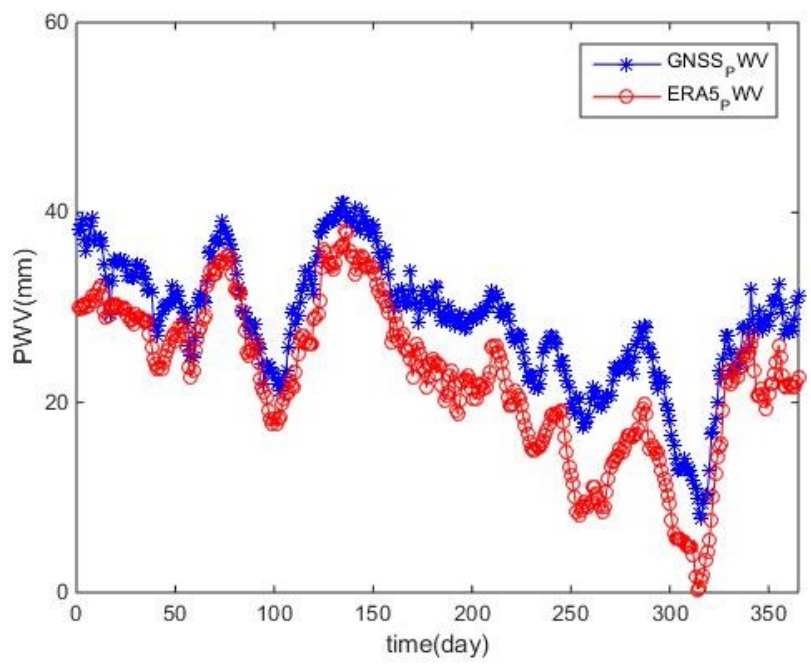

Figure 3. HKPC PWV

\section{CONCLUSION}

Based on the ZTD and PWV calculated from the measured data of 17 GNSS satellite positioning reference stations in Hong Kong, China, the accuracy of ZTD and PWV generated by ERA5 reanalysis data is analyzed. The results show that the bias value and RMSE value of ERA5-derived ZTD and GNSSderived ZTD in 2017 are both within $2 \mathrm{~cm}$, but the RMSE values are relatively high in each season, and the ZTD derived from the two is poor. In addition, compared with GNSSderived PWV, ERA5-derived PWV has better PWV accuracy, especially in spring. However, considering that the ZTD value estimated in some time periods is relatively inaccurate, it affects the quality of PWV. Subsequent control of the ZTD estimated quality for higher quality PWV values, in real time, ERA5 derived PWV and GNSS derived PWV comparison results will be a step up.

\section{REFERENCES}

Albergel, C., Dutra, E., Munier, S., Calvet, J. C., Munoz Sabater, J., de Rosnay, P., \& Balsamo, G. 2018. ERA-5 and ERA - Interim driven ISBA land surface model simulations: Which one performs better? Hydrology and Earth System Sciences, 22(6), 3515-3532.

B. Torres, V.E. Cachorro, C. Toledano, J.P. Ortiz de Galisteo, A. Berjón, A.M.De Frutos, N. Laulainen, 2010. Precipitable water vapor characterization in the Gulf of Cadiz region (southwestern Spain) based on Sun photometer, GPS, and radiosonde data. J. Geophys. Res.: Atmosphere, 115 (D18).

C.E. Holloway, J.D., 2010.NeelinTemporal relations of column water vapor and tropical precipitation. J. Atmos. Sci., 67 (4), pp. 1091-1105.

CHEN Qinming,SONG Shuli, ZHU Wenyao, 2012. An analysis of the accuracy of zenith tropospheric delay calculated from ECMWF/NCEP data over Asian area. Chinese Journal of Geophysics, 55 (5):1541-1548.).

G. Gendt, G. Dick, C. Reigber, M. Tomassini, Y. Liu, M. Ramatschi, 2004.Near real time GPS water vapor monitoring for numerical weather prediction in Germany. J. Meteorol. Soc. Jpn., 82 (1B), pp. 361-370.

H. Fudeyasu, K. Ichiyanagi, A. Sugimoto, K. Yoshimura, A. Ueta, M.D.Yamanaka, K. Ozawa, 2008.Isotope ratios of precipitation and water vapor observed in Typhoon Shanshan. $J$. Geophys. Res., 113, p. D12113.

Heffernan O, 2013. The dry facts. Nature, 501 (7468):S2-3.

Huang Weifang, Lou Yidong, Zhang Satellite, Liu Jingnan, 2018. The assessment of ZTD calculated from reanalysis over China. Science of Surveying and Mapping, 43(05):13-17.

J. Böhm, A. Niell, P. Tregoning, H. Schuh, 2006. Global Mapping Function (GMF): a new empirical mapping function 
based on numerical weather model data. Geophys. Res. Lett., 33 (7).

J.L. Davis, T.A. Herring, I.I. Shapiro, et al., 1985. Geodesy by radio interferometry: effects of atmospheric modeling errors on estimates of baseline length. Radio Sci., 20 (6) (J.L. Davis, T.A. Herring, I.I. Shapiro, et al.), pp. $1593-1607$.

J. Saastamoinen, 1972. Atmospheric correction for the troposphere and stratosphere in radio ranging of satellites. S.W. Henriksen, A. Mancini, B.H. Chovitz (Eds.), The Use of Artificial Satellites for Geodesy, vol. 15, American Geophysical Union (AGU), pp. 247-251.

K. Lagler, M. Schindelegger, J. Böhm, H. Krásná, T. Nilsson, 2013: Gpt2: empirical slant delay model for radio space geodetic techniques. Geophys. Res. Lett., 40 (6), p. 1069.

L. Yang, C. Hill, T. Moore, 2013. Numerical weather modeling-based slant tropospheric delay estimation and its enhancement by GNSS data. Geo Spatial Inf. Sci., 16 (3) (L. Yang, C. Hill, T. Moore), pp. 186-200.

M. Bevis, S. Businger, T.A. Herring, C. Rocken, R.A. Anthes, R.H. Ware, 1992. Gps meteorology: remote sensing of atmospheric water vapor using the global positioning system. Journal of Geophysical Research Atmospheres, 97 (D14), pp. $15787-15801$.

M. Bevis, S. Businger, S. Chiswell, T.A. Herring, R.A. Anthes,

C. Rocken, R.H.Ware, 1994. GPS meteorology: mapping zenith wet delays onto precipitable water. J. Appl. Meteorol., 33 (3), pp. 379-386.

Olauson, J. 2018. ERA5: The new champion of wind power modelling? Renewable Energy, 126,322-331.

P. Benevides, J. Catalao, P.M.A. Miranda, 2015. On the inclusion of GPS precipitable water vapour in the nowcasting of rainfall. Nat. Hazards Earth Syst. Sci. Discuss, 3, pp. 38613895 .
Qingzhi Zhao, Yibin Yao, Yao, Wanqiang, 2018a. GPS-based PWV for precipitation forecasting and its application to a typhoon event. J. Atmos. Sol. Terr. Phys., 1 (167), 124 133.

Qingzhi Zhao,Yibin Yao,Wanqiang Yao,Shubi Zhang, 2018. GNSS-derived PWV and comparison with radiosonde and ECMWF ERA-Interim data over mainland China. Journal of Atmospheric and Solar-Terrestrial Physics.

S.G. Jin, J.U. Park, J.H. Cho, P.H. Park, 2007. Seasonal variability of GPS-derived zenith tropospheric delay (19942006) and climate implications. J. Geophys. Res., 112 (D9), p. D09110.

T.A. Herring, R.W. King, S.C. McClusky, 2010 Documentation of the GAMIT GPS Analysis Software Release 10.4. Department of Earth and Planetary Sciences, Massachusetts Institute of Technology, Cambridge, Massachusetts.

T. Nilsson, L. Gradinarsky, 2006. Water vapor tomography using GPS phase observations: simulation results. IEEE Trans. Geosci. Rem. Sens., 44 (10), pp. 2927-2941.

Xiaoming Wang,Kefei Zhang,Suqin Wu,Zishen Li,Yingyan Cheng,Li Li,Hong Yuan, 2018. The correlation between GNSS-derived precipitable water vapor and sea surface temperature and its responses to El Niño-Southern Oscillation. Remote Sensing of Environment, 216.

Y. Yao, L. Shan, Q. Zhao, 2017. Establishing a method of short-term rainfall forecasting based on gnss-derived pwv and its application. Sci. Rep., 7 (1), p. 12465.

Yonglin Zhang,Changsheng Cai,Biyan Chen,Wujiao Dai, 2019 Consistency Evaluation of Precipitable Water Vapor Derived From ERA5, ERA-Interim, GNSS, and Radiosondes Over China. Radio Science, 54(7). 
The International Archives of the Photogrammetry, Remote Sensing and Spatial Information Sciences, Volume XLII-3/W10, 2020 International Conference on Geomatics in the Big Data Era (ICGBD), 15-17 November 2019, Guilin, Guangxi, China

Zhaoyang Wang,Xinghua Zhou,Yanxiong Liu,Dongxu Zhou,Huayi Zhang,Weikang Sun, 2017. Precipitable water vapor characterization in the coastal regions of China based on ground-based GPS. Advances in Space Research, 60(11). 